\title{
Bullying and Quality of Life of Health Professionals
}

\author{
Luciana de Barros Correia Fontes* \\ Department of Clinical and Preventive Dentistry, Federal University of Pernambuco (Universidade Federal de Pernambuco), Brazil
}

Received: 㘹July 14, 2018; Published: 畊July 19, 2018

*Corresponding author: Luciana de Barros Correia Fontes, Department of Clinical and Preventive Dentistry, Federal University of Pernambuco (Universidade Federal de Pernambuco), Brazil

\section{Opinion}

We live in a unique moment in the world context, where it is necessary to emphasize that respect for the other, in its diversity as an individual, constitutes the north for a good coexistence and a fundamental element for the health. And this does not represent novelty. However, changing patterns of performance indicators do not seem to contemplate, in a balanced way, the universe of possible characteristics of human beings; implement pre-established roadmaps that can lead to a high level of stress and overcome inherent adaptation limits. I direct this approach for the health team. Over the course of the last few decades we have observed extreme exhaustion, lack of service, lack of motivation, commitment to the physical and mental health not only of professionals, but of technicians and academics, from the training process. In an attempt to understand the impacts on the quality of life of this target group it is recorded the "bullying". This phenomenon has been observed and reported among university students, employees and health professionals. In this context, it is important to highlight the expansion of the internet and social networks, which, if on the one hand constitute a space of aggregation in interpersonal relations, in the opposite sense comprise a hostile speech environment motivated by envy, prejudice and intolerance.

There needs to be a construction of the collective consciousness. Remember that conflict is something inherent to the human being, based on cultural, social, gender, opinion and interest differences. Also, empathy, resilience and tolerance as necessary coexistence skills present the limit of maintaining individuality, ethics and respect for others. If, on the one hand, it is argued that ethics and morality are values or principles that can change over time, according to the customs of a particular group or the type of activity performed; to establish the notion of the measure that should not be surpassed, is a reflection of what it would otherwise be. A greater concern exists regarding corporate bullying, with practices of embarrassment and depreciation of the image in the workplace. Intrigue, manipulation, and intimidation usually associated with individuals who share ideas, affinities, or benefits and adopt a policy of exclusion for other team members, especially when they consider them a potential threat to entrenched interests simply by behaving or thinking differently (horizontal or vertical commands). The aggression done intentionally and repeatedly causes distress and pain to the victim in question, who usually becomes more fragile in their self-esteem and to react to this attack. And the result will hardly be positive; at least favoring a hostile environment. Preventing, identifying, reversing and combating bullying is probably the best strategy for the healthy construction of health workers. (c) (i) This work is licensed under Creative

To Submit Your Article Click Here: Submit Article

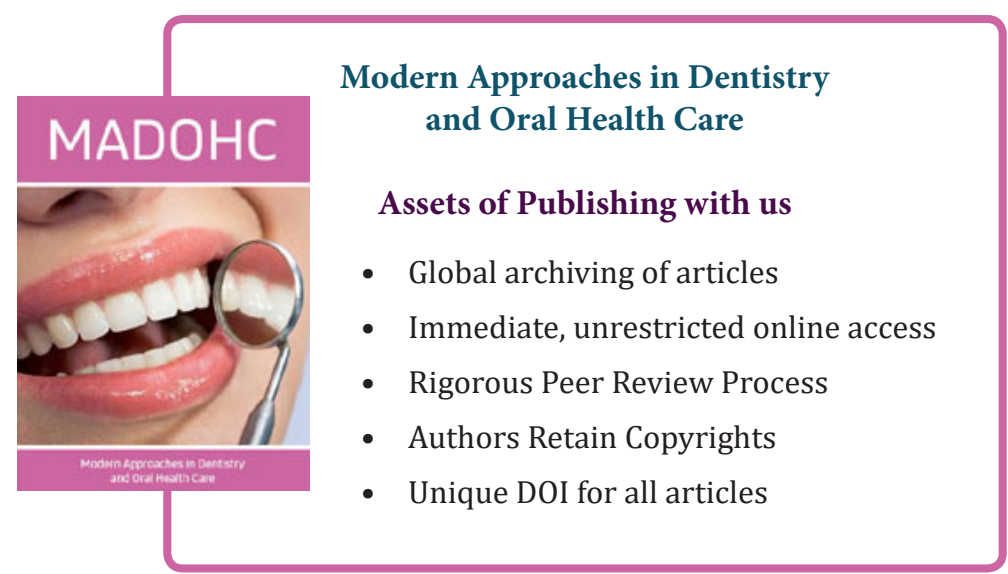

